\title{
Transient Stability Study of a Reality 500kV Power System Using Statcom
}

\author{
Tran Thi Ngoat ${ }^{1}$ and Le Ngoc Giang ${ }^{2}$ \\ ${ }^{1}$ School of Electrical Engineering, Wuhan University, Wuhan 430072, China \\ Hung Yen University of Technology and Education, Hungyen Vietnam \\ ${ }^{2}$ School of Electrical Engineering, Wuhan University, Wuhan 430072, China \\ lengocgianglinh@gmail.com
}

\begin{abstract}
Many of papers refers to study of application for Flexible Alternative Curent transmission Systems (FACTS). Especially for using reactive compensators for $500 \mathrm{kV}$ powersystem in order to increase the static voltage stability margin and transient stability enthancement have considered. This paper presents a simulation model of the Static Synchyonous Compensator (STATCOM) is developed to study its dynamic characteristics. The developed STATCOM is connected at the Point of Common Coupling (PCC) of the Doubly Fed Induction Generator (DFIG) wind turbine system connected to the meak distribution grid for steady state and dynamic voltage regulation purpose. The purpose of this paper is to solve the above problems in order to suggest a solution of the appropriate shunt conpensator for a reality 500KV power system. Simulation results have shown that STATCOM helps to keep the steady state terminal voltage of the DFIG system to its rated voltage during the entire operation region of the DFIG. STATCOM maintains the fast voltage regulation (or voltage restoration) at the PCC during step change in reactive load causing voltage swelling or sagging. STATCOM does this by dynamically exchanging the reactive powe with the power grid. The results of this work are of certain practical significanced applicable value.
\end{abstract}

Keywords: FACTS, SFATCOM Transient Stability of Power System, DFIG

\section{Introduction}

Power systems components mainly consist of generators, transmission lines, transformers, switches, active or passive compensators and loads. Power system networks are complex systems, nonlinear, non-stationary, prone to disturbances and faults [1].

Voltage regulation can be maintained in the power system by supplying or absorbing the reactive power. Hence, the voltage regulation at a particular node in a power system is directly related to the reactive power capability of the devices directly connected to that node or present in the vicinity of that node [2]. Although, the DFIG-based wind turbines are able to control active and reactive power independently, the reactive power capability of those generators is limited. This problem is more severe in the case of DFIG wind turbines connected to weak power grids having under voltage condition as the reactive power capability gets even more degraded. Hence an additional local reactive power source is needed. Moreover, the power generation trend these days is shifting from the transmission network to the distribution grid, i.e., decentralization of power generation. As a result, it is becoming more difficult to control the voltage in the entire transmission network from conventional power stations only. Hence grid companies are installing dedicated local voltage control equipments like capacitor banks, 
FACTS devices and are demanding distributed generation equipments to have their own reactive power capability as a result there cannot be any exemption for wind turbines [3].

Furthermore, because of the increased penetration level of wind turbines in the power grid, utility companies are asking to fulfill certain criteria (grid codes) for the interconnection of wind turbines to the power grid. The grid codes mainly requires that wind turbines remain connected to the network during temporary disturbances in the network like voltage swelling and sagging, and step change in load. Wind turbines cannot be a VAR neutral (or consumer). Now they must be able to provide reactive power and adjust their control according to the necessity of the system. To meet this requirement, the DFIG wind turbine system should be able to respond fast whenever there is disturbance in the system by supplying or absorbing reactive power. Hence, the added reactive power source should have good dynamic response [4].

FACTS devices are dynamic reactive power sources which are becoming more and more popular in power system application these days because of rapid advancement in high-current, high-power semiconductor device technology, digital control, and signals conditioning $[5,6,7]$. In this study, a voltage source converter (VSC) PWM technique based STATCOM is modeled, its control system is designed and the use of STATCOM (a FACTS levice) at the PCC is investigated for voltage regulation purpose in the DFIG wind turbine system. The voltage regulation study is done by creating three phase symmetrical fault and roltage swelling and sagging at the PCC where local load is also connected.

\section{Statcom Description}

According to the IEEE, STATCOM system is a static synchronous generator operated as a static compensator connected in parallel whose output curent (inductive or capacitive) can be controlled independently of the AC system voltage.

A charged capacitor acts as a source of direet current. This current feeds an AC/DC power converter, which produces a set of outputs with controllable three-phase voltages. Also, the frequency of these voltages is the AC ystem frequency. The AC/DC power converter is controlled by PWM techniques, so the output voltages achieved are practically sinusoidal. These controllers are possible by the high switching frequency of the IGBT, GTO, IGCT or IEGT transistors of the power converter [8]. The system connects to the grid via a transformer, Figure 1.

The system is characterized by a rapid response time and its ability to provide a control voltage to the connection point through reactive power compensation. It can be used for filtering harmonics, improving aransient and dynamic stability, dynamic over voltages and under voltages, voltage collapse, steady state voltage, excess reactive power flow and undesirable power flow [9]. This enables that the wind farm, for instance, to have a better response in voltage dips as well as more stable system.

Usually, STATCOM is installed at the MV bus in the wind farm. Its aim is to help the wind farm in situations of voltage dips, voltage regulation, power factor control and power flow stabilizing.

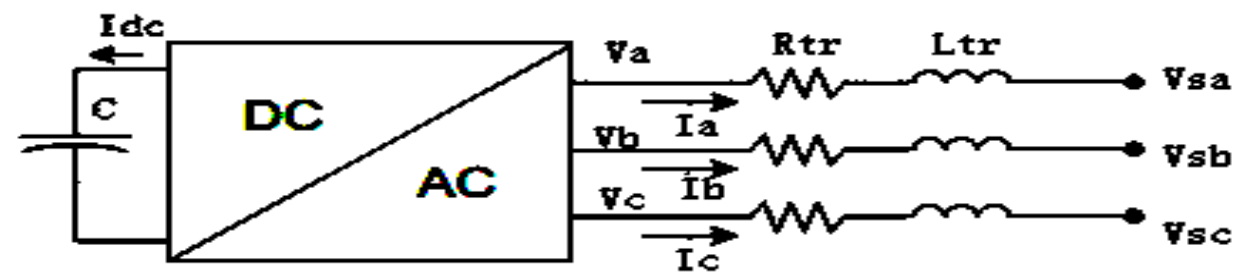

Figure 1. STATCOM Description 


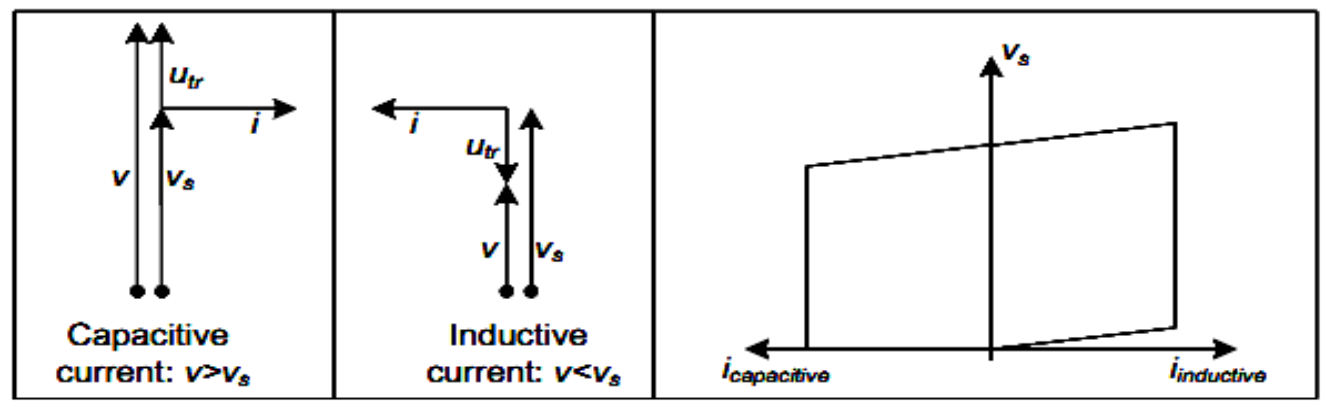

Figure 2. Operating Principle and Operation Area of STATCOM

The operating principle of STATCOM is as follows:

- If $\mathrm{v}=\mathrm{v}_{\mathrm{s}}$ (pu values), no current flows through Rtr and Ltr.

- If $\mathrm{v}>\mathrm{v}_{\mathrm{s}}$, current flows through Rtr and Ltr. As the impedance is essentially mductive, the current phasor is perpendicular to vs and v voltages. STATCOM injects reactive current to the grid (capacitive current).

- If $\mathrm{v}<\mathrm{v}_{\mathrm{s}}$, current flows through Rtr and Ltr. This time the current flow is opposite to the previous, which implies that STATCOM absorbs reactive power from the grid (inductive current).

\section{System Description}

\subsection{Reasons for Choosing the Statcom}

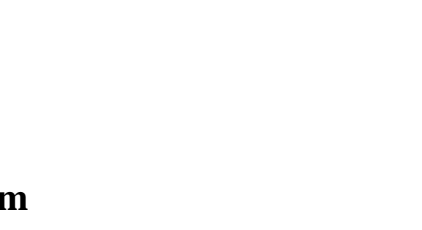

Capacitors are usually connected to fixed speed wind turbines to enhance the system voltage because they are the sink of reactive power. Mechanically switched fixed shunt capacitors can enhance the system's voltage stability limit, but is not very sensitive to voltage changes, i.e., dynamic response of capacitors is not good.

STATCOM is the best option for dynamic compensation of reactive power because at voltages lower than the normal voltage range, it can generate more reactive power than other FACTS devices like Static Yar Compensator (SVC), which is very similar to STATCOM for functional compensation apablity but its fundamental operating principle is different. A STATCOM functions as a shunt-connected synchronous voltage source whereas a SVC operates as a shunt-confected controlled reactive admittance. This difference accounts for the STATCOM's supefion functional characteristics, better performance, and greater application flexibility than those attainable with a SVC. The STATCOM is able to control its output current over the rated maximum capacitive or inductive range independently of AC system voltage, whereas the maximum attainable compensating current of the SVC decreases linearly with AC voltage. In addition, the STATCOM normally exhibits a faster response as it has no delay associated with the thyristor firing.

The output of the wind power plants and the total load vary continuously throughout the day. Reactive power compensation is required to maintain normal voltage levels in the power system. Reactive power imbalances, which can seriously affect the power system, can be minimized by connecting the STATCOM. The STATCOM can also contribute to the low voltage ride through requirement because it can operate at full capacity even at lower voltages.

Moreover, the STATCOM can be connected to any voltage level in power system using coupling transformer of appropriate turn ratio. The STATCOM can be easily connected to an already installed wind turbine system which has a voltage regulation problem. 


\subsection{Location of the STATCOM}

Many study show that STATCOM provides effective voltage support at the bus to which it is connected to. Hence, in this study, the STATCOM is placed at the PCC bus because of the following two reasons:

The location of the reactive power support should be as close as possible to the point at which the support is needed because of the change in voltage and consequent power loss (I2R loss) in transmission line associated with the reactive power flow.

In the studied system, the effect of voltage change is most significant at this node.

\subsection{Connecting STATCOM at the PCC with DFIG-based Wind Energy Conversion System (WECS)}

It can be clearly seen in Figure 3 that the reactive power capability of DFIG is not enough to maintain required power factor at the PCC when the DFIG is operating at higher rotor speed (more than $1.1 \mathrm{pu}$ and corresponding output active power being $0.82 \mathrm{pu}$ ). Aceording to grid code requirement, WECS should be operating up to 0.9 lagging pf to support the stability of the connected power system. So to meet this requirement, we need extra reactive power source. Here STATCOM is proposed as a dynamic reactive power source because of its many advantages compared to other reactive power sources. Here, the STATCOM is connected at the PCC as shown in Figure 4 and the power grid is modeled as an infinite bus, i.e., constant voltage source, the reactive power required in plovided by the combination of DFIG and STATCOM.

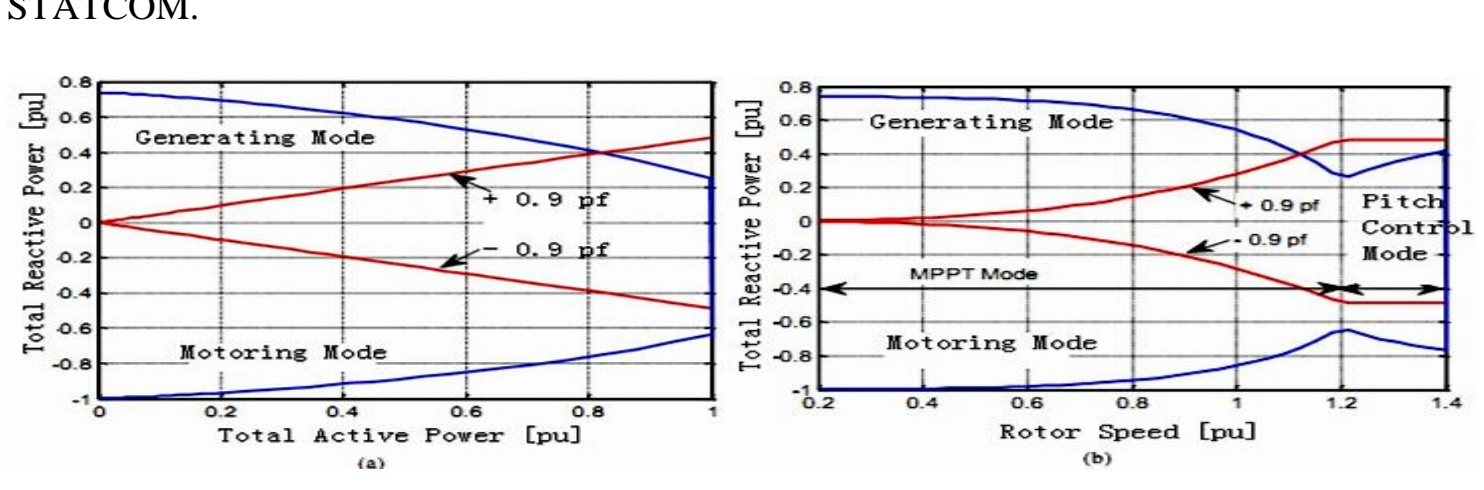

Figure 3. DFIG Steady State Reactive Power Capability Curves

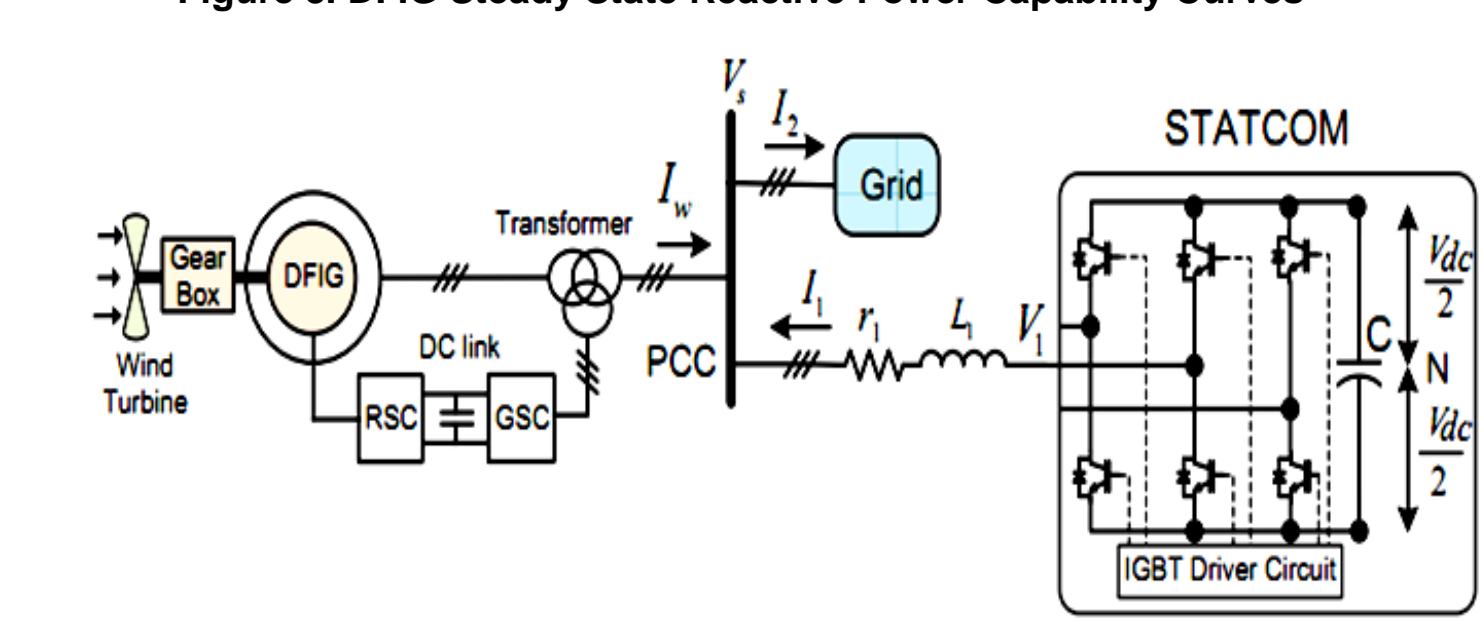

Figure 4. STATCOM Connected to DFIG-based WECS at PCC 


\section{Simulation Results}

\subsection{Flowchart for Plotting PQ Diagram of Dfig-based WECS with Statcom}

In this study, a model of the STATCOM during the steady state is used to derive the reactive power output expression from STATCOM and it is co-related with the DFIG reactive power capability to draw the reactive power capability curve of the combined STATCOM and DFIG system.

The flowchart for drawing reactive power capability curve (P-Q diagram) of the DFIG wind turbine system with STATCOM at the PCC to meet the reactive power requirement (or power factor requirement) is shown in Figure 5.

The reactive power capability diagram of overall DFIG-based WECS with STATCOM connected at PCC is shown in Figure 6. When the DFIG does not have enough reactive power, STATCOM supplies the additional reactive power to maintain 0.9 pf during entire operation region of the DFIG to meet the grid code requirement. As depicted in Figure 6, STATCOM has to supply maximum of 0.2 pu reactive power, which gives the rating of the STATCOM required to fulfill the steady state reactive power (or power factor) requirement.

Therefore, steady state characteristics of the DFIG-based WECS and the steady state reactive power capability of the DFIG is shown in the form of PQ diagram. It is observed that, DFIG has limited reactive power capability so installation of STATCOM at the PCC as an additional reactive power source to fulfill the reactive power requirement is proposed. In this study, the use of STATCOM connected at the PCC to regulate the steady state voltage as well as improving the dynamic response of DFIG wind turbine system during grid side disturbance is discussed.

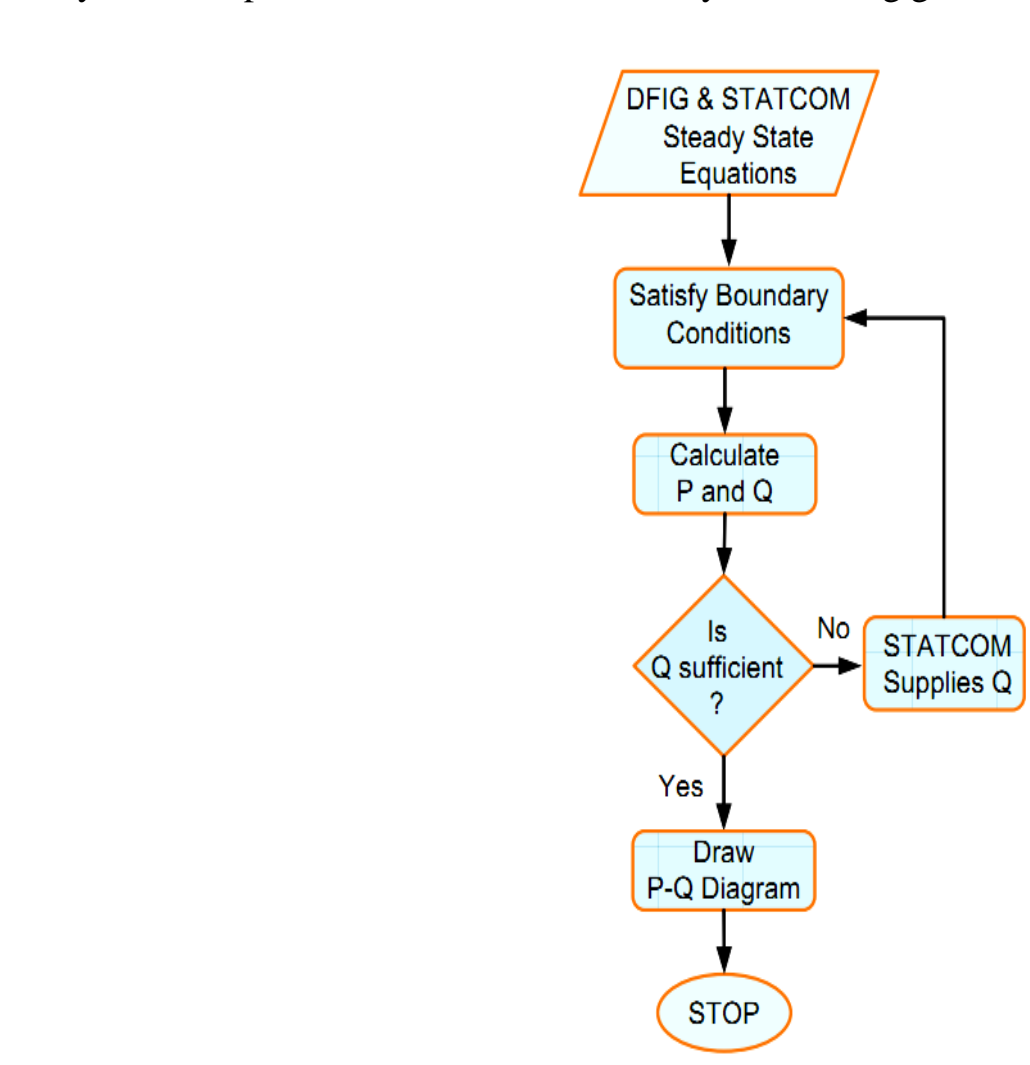

Figure 5. Flowchart for Plotting PQ Diagram of DFIG-based WECS with STATCOM 


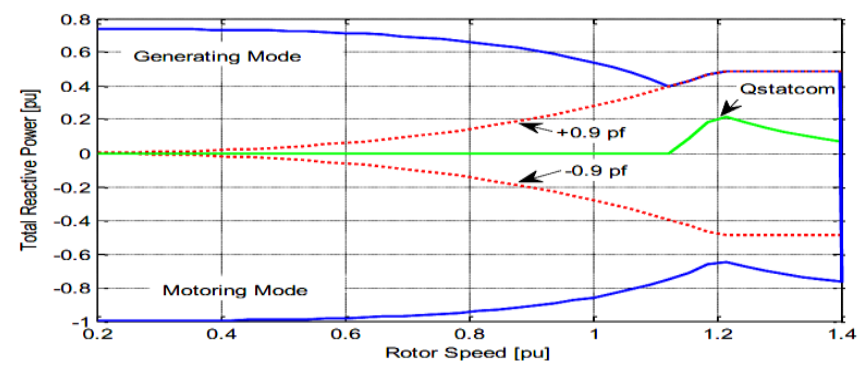

Figure 6. Reactive Power Capability Diagram of Overall DFIG-based WECS with Statcom at Various Rotor Speeds

\subsection{Disturbances Mitigation in the DFIG-based Wind Turbine System Using the STATCOM}

With the increased penetration of wind in the power grid, the grid operators are forced to tighten their grid connection rules in order to limit the effects of wind powe parks on power network quality and stability. Important issues are the seady state active and reactive power governing capability, continuously acting voltage contro, and disturbance tolerant system like voltage sagging and voltage swelling. This means, the grid codes demand that wind farms stay connected to the grid and stabilize the grid voltage in case of disturbances in the grid.

\subsubsection{Test System}

Figure 7 demonstrates the single line diagram of the test system studied in this study. A 1.5 MW DFIG wind turbine system is conmected to the distribution network at the PCC bus where a STATCOM is connected to regulate the terninal poltage. Three different types of loads, a linear RL load, a constant load (P, Q) and a noplinear load (Pnon, Qnon) are also connected in shunt to the same PCC bus. The rated wind speed of $12 \mathrm{~m} / \mathrm{s}$ is inputted to the turbine so as to generate rated active power output during the entire study period. The GSC is always supplying its optimum reactive power ( 0.3 pu, i.e., equal to $30 \%$ of total power rating of DFIG). The distribution network is modeled as weak $(\mathrm{Xg} / \mathrm{Rg}=5)$.

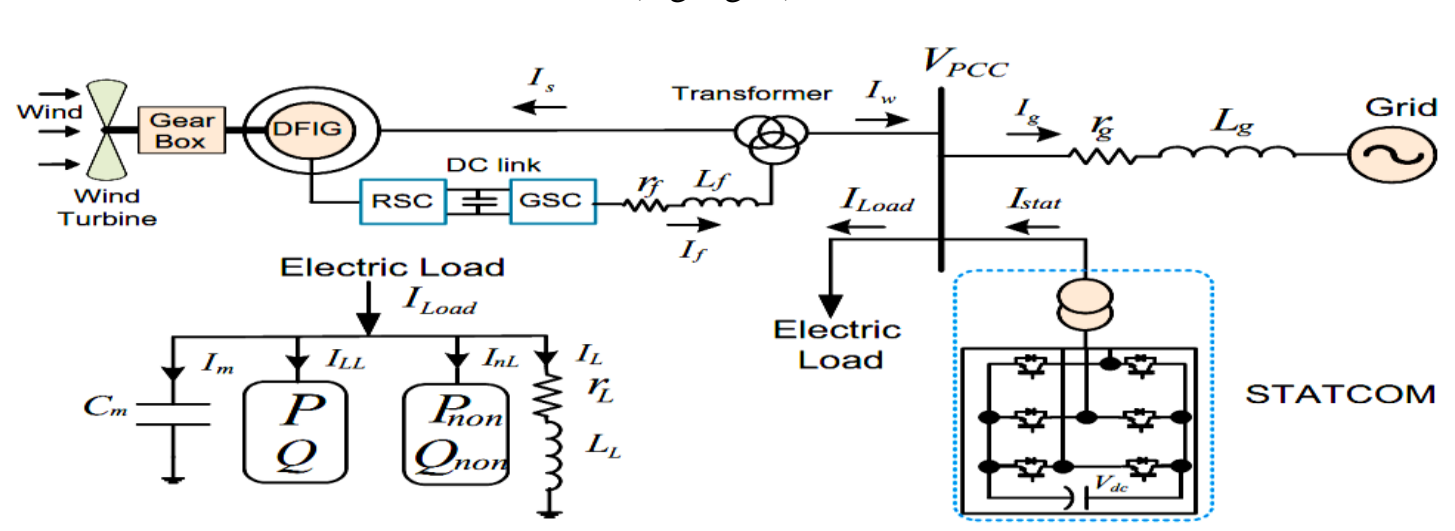

Figure 7. Single Line Diagram of the Studied Power Network

Now with all those above described models of the STATCOM, DFIG, loads and their controls are implemented in MATLAB/Simulink software. Voltage swelling and voltage sagging study is performed to assess the effectiveness of the implemented control system which is described in the below. 


\subsubsection{Voltage Swelling Study}

Voltage swelling is the brief increases in voltage over the time range from milliseconds to few seconds. Among the grid disturbances, the voltage swell is a critical event that can be caused by abrupt switching off large loads or switching on capacitive load or damaged/loose neutral connection in the power system. Here the symmetrical voltage swelling of $22 \%$ is created by step increase in capacitive constant load at $\mathrm{t}=5 \mathrm{sec}$. All the other loads remain same. In the absence of the STATCOM, when the capacitive load is increased instantly, the weak grid cannot respond quickly by absorbing additional reactive power and the DFIG output power is already regulated to its optimum value so voltage at the PCC increases as shown in Figure 8(a). With the STATCOM connected at the PCC, same voltage swelling is created again but this time STATCOM responds quickly by absorbing additional reactive power; as a result, the voltage at the PCC is regulated close to 1 pu with small overshoot shown in Figure 8(a) and Figure 8(b).

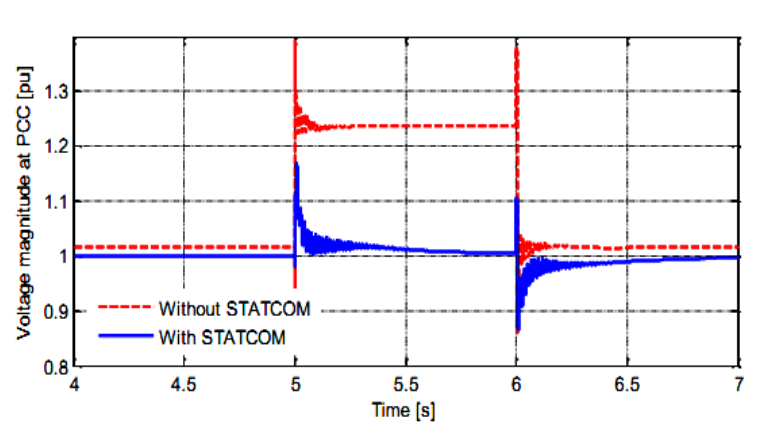

(a)

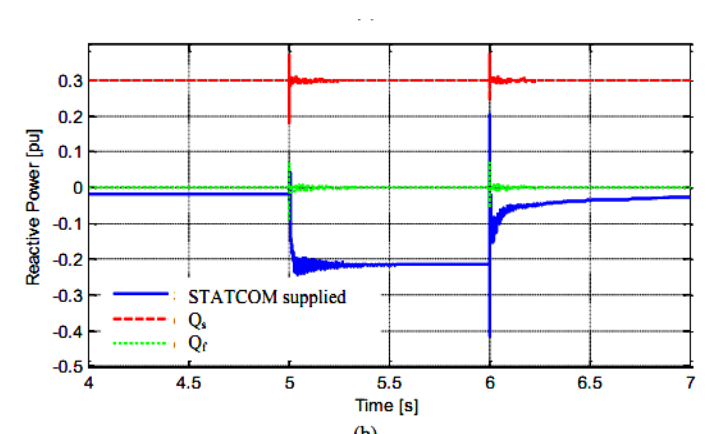

(b)

Figure 8. The PCC Voltage at the DFIG Wind Turbine with and Without STATCOM During 22\% Symmetrical Voltage Swell

\subsubsection{Voltage Sagging Study}
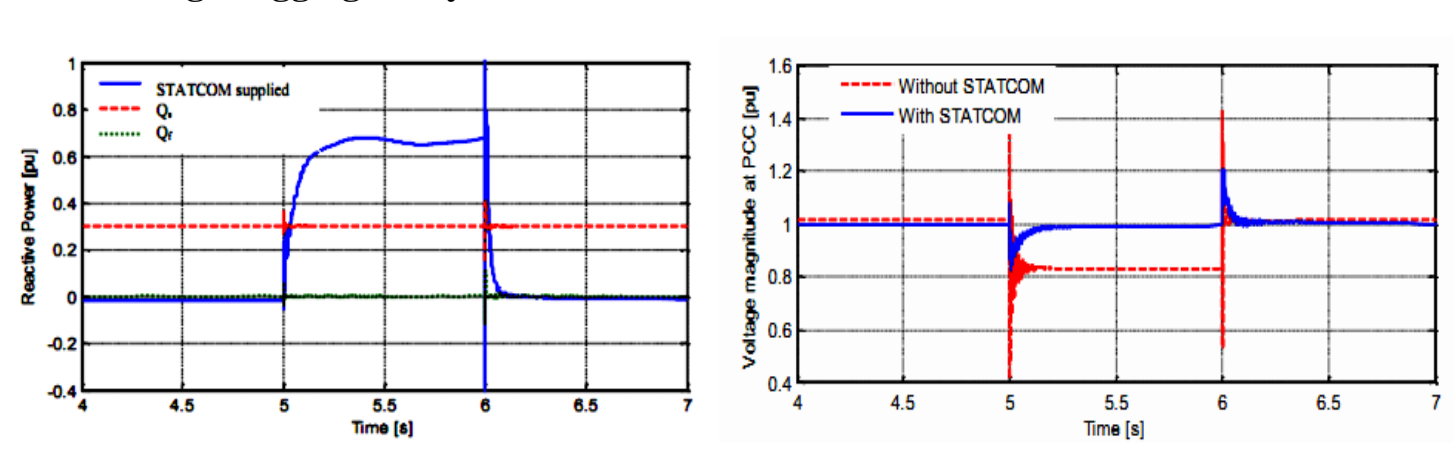

\section{Figure 9. The PCC Voltage at the DFIG Wind Turbine With and Without STATCOM during $18 \%$ Symmetrical Voltage Sag}

Voltage sagging is the momentary reduction in voltage over the time range from milliseconds to few seconds. The voltage sagging is the most common type of grid disturbance which is caused by abrupt switching on large inductive loads like electrical heater, motor starting or abrupt increase in source impedance typically caused by loose connection. In this study, the symmetrical voltage sagging of $18 \%$ is created by step increase in inductive constant load at $\mathrm{t}=$ $5 \mathrm{sec}$. All the other loads remain constant. In the absence of the STATCOM, when the inductive load is increased instantly, the weak grid cannot respond quickly by supplying required surplus 
reactive power and the DFIG output power is already regulated to its optimum value. As a result, the voltage at the PCC drops as shown in Figure 9(a). When the STATCOM is connected at the PCC and the same voltage sagging is created; in that case, STATCOM responds quickly by supplying additional reactive power. As a result, the voltage at the PCC is regulated closely to 1 p.u. with small overshoot shown in Figure 9(b).

\section{Identify Optimal Type of Reactive Power Generating Source in Fact of Power System}

The scale of wind power plants is increasing continuously in Vietnam. Wind energy conversion systems are very different in nature from conventional generators. Therefore dynamic studies must be addressed in order to integrate wind power into the power system. The impact of this wind power on voltage distribution levels has been addressed in the literatues.

Vietnam's 500kV grid system in 2015 was included in the survey of which the southern grid is considered to compensate reactive power because of large load demand wh chis dramatically increased. The two receiving/transmitting reactive power devices $\triangleleft$ with equivalent size, which are included in the survey of stability in the domain time, are SVC and ST ATCOM.

In case of calculation with the capacity mobilized from the North to the South at the boundary value of $1550 \mathrm{MW}$, transmission capacity in $500 \mathrm{kV}$ grid connecting the Middle with the South is quite large. To evaluate the ability to improve the stability of the reactive power generating devices, the considered incident scenario, is that,incident is occurred on 3 permanent phases in $500 \mathrm{kV}$ lines from Di Ling to Tan Pinh, fault location is near Tan Dinh $500 \mathrm{kV}$ transformer station; main relay does not work, the preventive relays system send the turn-off delay signal with the time ranging from $0.5 \mathrm{sec}$ to $0.8 \mathrm{sec}$.

The results of analysis of phase angular oscillation of 1000MW generators in Tra Vinh show that after short-circuit breaking, breaking time is $0,7 \mathrm{sec}$; amplitude of phase angle of Tra Vinh generator in case of using reactrve power compensation source created by SVC is greater than that in case of using STATCOM. With large amplitude if time of short-circuit elimination is increased, the system will be unstable.

Another survey with the same ineident case but with short-circuit breaking time extending to $0.8 \mathrm{sec}$ is conducted. The Southern electrical system in case of reactive power compensation generated by SVC was unstable, while in case of that generated by STATCOM, the system still remains the stability.

Basing on the above calculation it can be concluded that in term of stability in the domain time, the reactive power compensation system generated by STATCOM will be controlled more quickly, flexibly and reliably than SVC.

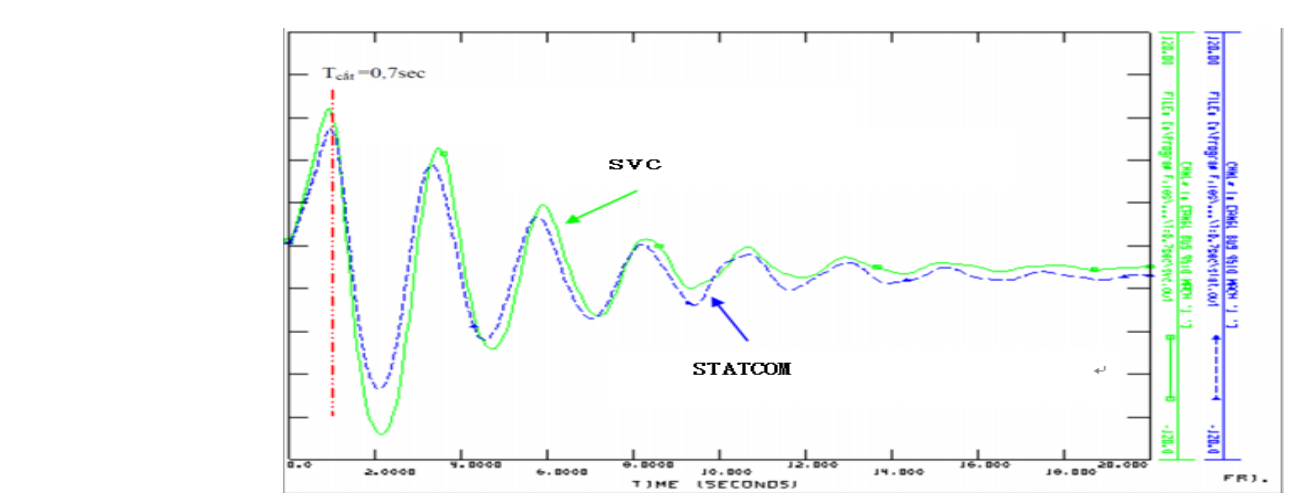

Figure 10. Phase Angle Oscillation of 1000MW Generating Set in Tra Vinh 


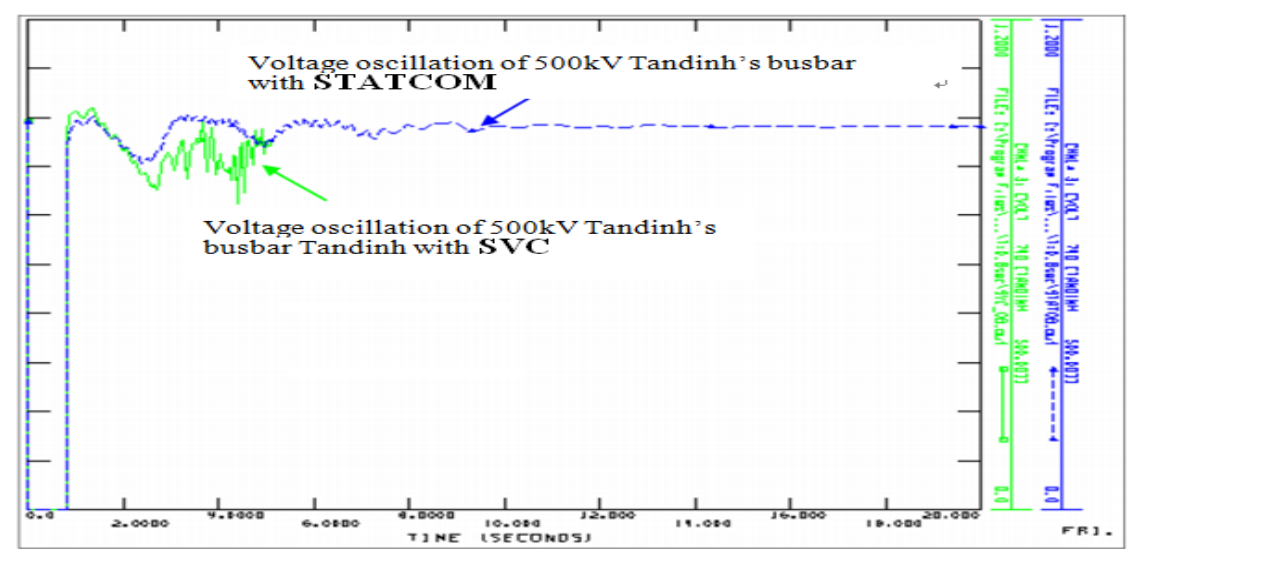

Figure 11. Voltage Oscillation of 500kV Tandinh's bus bar

\section{Conclusion}

In this study, the power system stability enhancement via STATCOM and SVC stabilizers is presented and discussed. In this paper the modeling and controller des gn of STATCOM is shown. The support provided by the STATCOM to regulate steady state voltage and to improve dynamic response of the DFIG wind turbine system during disturbances in the grid side isexplained clearly with the help of simulation results. The dynamic voltage regulation during voltage swelling and voltage sagging and its mitigation using STATCOM is discussed and is well supported by the simulation results. An effort is made to assess voltage stability and security of multi-bus power system in presence of STATCOM and SVC. A comparative study on effectivenes of STATCOM and SVC in improvement of voltage stability and security has also been presented. STAFCOM is found to be more effective than SVC to ensure voltage stability and security, at the same time, it is also capable to considerably reduce reactive power line loss. The results of this work are of certain practieal significance and applicable value. Based on such calculation, For Vietnam's 500ky grid, power compensation by using STATCOM will improve operation stability better than using SVC.

\section{References}

[1] G. Glan man, "FACTS Flexible Alternating Current Transmission Systems", EEH - Power Systems Laborato y ETH Z̈urich, (2005).

[2] J.G.Singh, S.N.Singh and S.C.Srivastava, "An Approach for optimal Placement of Static Var Compensators Based on Reactive Poyer Spot Price”, IEEE Trans. On Power Systems, vol. 22, no. 4, (2007).

[3] Chong Han, Alex Q Huang, Mesut E. Baran, Subhashish Bhattacharya, Wayne Litzenberger, Loren Anderson, Anders L. Johnson, and Abdel-Aty Edris, "STATCOM Impact Study on the Integration of a Large Wind Farm into a Weak Loop Power System," IEEE Trans. on Energy Conversion, vol. 23, no. 1, (2008).

[4] B. Singh, R. Saha, A. Chandra and A. Haddad, "Static synchronous compensators (statcom): a review", IET Power Electronics 2, (2009), pp. 297-324.

[5] Q Song W. Liu and Yuan, "Multilevel optimal modulation and dynamic control strategies for statcoms using cascaded multilevel inverters", IEEE Transactions on Power Delivery, vol. 22, (2007), pp. 1937-1946.

[6] B. Ronner, P. Maibach and Thurnherr, "Operational experiences of statcoms for wind parks", IET Renewable ower Generation 3, (2008), pp 349-357.

[7] R. Haijun, "A Novel effective wind speed soft measurement model for wind turbine", International Journal of Applied Mathematics and Statistics, vol. 50, no. 20, (2013).

[8] L. Qi, J. Langston and Steurer, “Applying a statcom for stability improvement to an existing wind farm with fixed-speed induction generators", Power and Energy Society General Meeting - Conversion and Delivery of Electrical Energy in the 21st Century (2008).

[9] B.-J. Yang, Q. Chao, T.-J Yuan, H.-D. Yi, "Research of STATCOM Impact on Wind Farm LVRT and Protection”, TELKOMNIKA Indonesian Journal of Electrical Engineering, vol 10, no 8, (2012). 


\section{Authors}

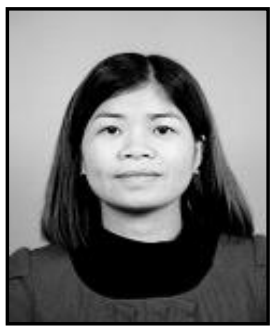

Tran Thi Ngoat, she was born in HungYen,Vietnam, on February 03, 1978. From 2010 to 2014, she is a Ph.D Student of Wuhan University, School of Electrical Engineering, Her main research interests are power electronics technology application and power quality control. Currently, she is a lecturer at Hung Yen University of Technology and Education.

ngoat_hy@yahoo.com

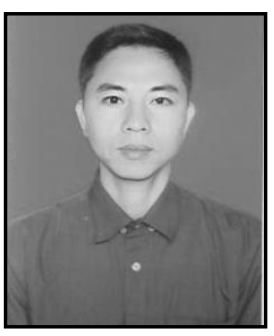

Le Ngoc Giang, he was born in Hanoi, Vietnam, on Jtity 21, 1975. Currently, he is a Ph.D Student of Wuhan University, School of Electrical Engineering, His main research interests are power system control and power system stability analysis, smart grid demand response, building automation system, and renewable energy.

lengocgianglinh@gmail.com

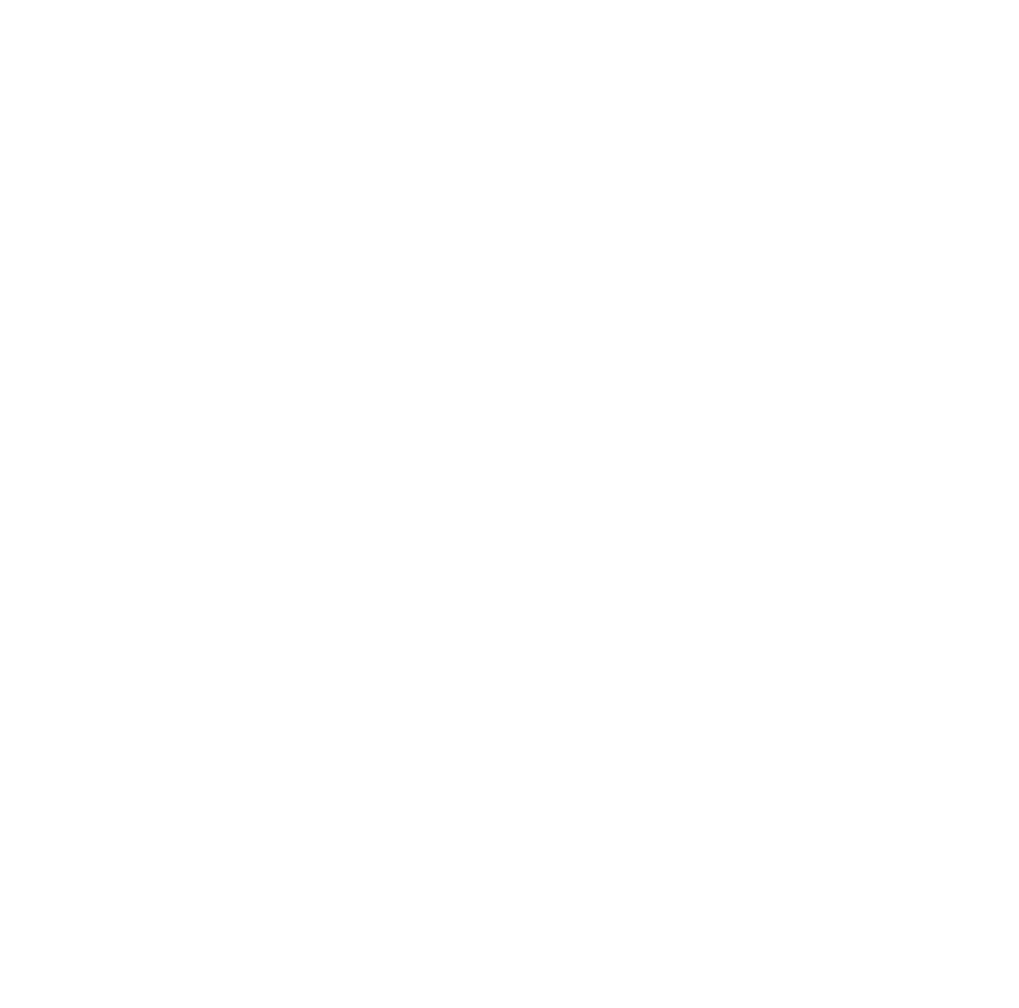

